\begin{tabular}{|c|c|c|}
\hline & Int.J.Curr.Microbiol.App.Sci (2016) 5(10): 156-165 & \multirow{2}{*}{ 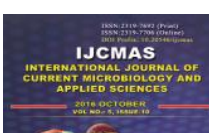 } \\
\hline & \multirow{4}{*}{$\begin{array}{l}\text { International Journal of Current Microbiology and Applied Sciences } \\
\text { ISSN: 2319-7706 Volume } 5 \text { Number } 10(\mathbf{2 0 1 6 )} \text { pp. 156-165 } \\
\text { Journal homepage: } \underline{\text { http://www.ijcmas.com }}\end{array}$} & \\
\hline & & \\
\hline EXCELLENT & & \\
\hline PUBLISHERS & & wwwijijemas com \\
\hline
\end{tabular}

Original Research Article

http://dx.doi.org/10.20546/ijcmas.2016.510.018

\title{
Study of Candida Colonization and Candidemia in Neonates Admitted in Neonatal Intensive Care Unit at a Tertiary Care Institute of Bikaner, Rajasthan, India
}

\author{
Kavita Bansiwal $^{1}$, Abhishek Binnani ${ }^{1}$ and Priyanka Soni Gupta ${ }^{2} *$ \\ ${ }^{1}$ Department of Microbiology, S. P. Medical College, Bikaner, Rajasthan, India \\ ${ }^{2}$ Department of Microbiology, Jawahar Lal Nehru Medical College, Ajmer, Rajasthan, India \\ *Corresponding author
}

\section{A B S T R A C T}

\section{Keywords}

Candida, preterm neonate, antifungal agent candidemia.

\section{Article Info}

Accepted: 12 September 2016 Available Online: 10 October 2016
The incidence of colonization and infection with Candida species has risen dramatically in the past decade with high rates of carriage in neonates, especially pre-terms, attributed to the advancement in medical field, life support systems, relative immunodeficiency, extensive use of broad spectrum antibiotics. Therefore we conducted this study to determine the colonization and candidemia in neonates admitted to neonatal intensive care unit along with its risk factors and possible maternal and nosocomial source. Isolated candida species was identified and their susceptibility to different antifungal agent determined. This study was carried out in the Department of Microbiology, S.P. Medical College from March 2012 to March 2013 on a total of 2132 samples collected from neonates admitted to neonatal intensive care unit of department of paediatric and labour room, P.B.M. Hospital, Bikaner, Vaginal swabs from pregnant women, swabs from hands of health care staff in NICU \& from nasogastric tube and iv line. Candida colonization rate was $47.31 \%$ in neonates admitted to NICU, more frequently in preterm neonates with IV antibiotics. Candidemia was $11.1 \%$ in neonates of NICU. Candida albicans was the most common species causing colonization and Candidemia. All candida species were susceptible to all antifungal agents except Candida krusei \& Candida glabrata which were highly resistant to Fluconazole. I.V. antibiotics, preterm neonates, low birth weight, RDS, Ventilation therapy and prior Candida colonization were identified as significant risk factors. Candida Parapsilosis is an emerging fungal pathogen and incidence of infection caused by it may continue to rise.

\section{Introduction}

Candida infection has increased steadily in incidence over last two decades. Candida spp. are currently considered the fourth most common cause of hospital acquired systemic infection (William et al., 2002).
They are the third most frequent causal agent of late onset sepsis in preterm neonate (Chapman, 2007; Stoll et al., 2002) with crude mortality rate of $30 \%$ to $75 \%$ (Karlowicz et al., 2002; Makhoul et al., 2002). Candida species also account for 9 to 
$13 \%$ of all blood stream isolates in NICUs (Agarwal et al., 2004).

Colonization with Candida in the neonate is believed to be secondary to either vertical transmission from the mother or horizontal transmission (nosocomial acquisition) in the nursery. The risk of vertical transmission is increased because the rate of vaginal colonization with Candida in pregnant women $(\sim 30 \%)$ is two to three times the rate of colonization in non pregnant women (Waggoner-Fountain et al., 1996).

During the past two decades invasive fungal infections (IFIs) have become an increasingly important problem in preterm infants hospitalized in the Neonatal Intensive Care Unit (NICU) (Benjamin et al., 2006; Chapman, 2007). It is generally observed that most infant candidiasis is thought to be endogenously acquired through prior colonization of different parts of the body (Asmundsdottir et al., 2008; Blot et al., 2008; Bendel, 2003).

The high (25-60\%) mortality rate is related to the difficulty to make an early diagnosis because of reduced sensitivity of diagnostic tests, non-specific clinical signs and to inadequate and / or delayed treatments (Castagnola et al., 2009). Recently, in a single center study, fluconazole prophylaxis has been shown to be beneficial in preventing candidemia (Kaufman et al., 2001).

The majority of neonatal Candida infections are caused by $C$. albicans, but other species of Candida have also emerged as important opportunistic pathogen, notably $C$. tropicalis, C. Glabrata and C. Parapsilosis (Roilides et al., 2003).

Till date no enough study have been undertaken on Candida colonization and candidemia in neonates admitted in neonatal intensive care unit at tertiary care unit in Rajasthan state. Therefore the present study was undertaken to find Candida colonization and candidemia in neonates admitted in neonatal intensive care unit at tertiary care unit in the northwest region of the state.

\section{Materials and Methods}

This prospective study was conducted between March 2012 to March 2013 on a total of 2132 samples, in the Department of Microbiology, S.P. Medical College, Bikaner.

The following samples were collected -1 . Swabs from oral, rectal, umblical and groin area of neonates on the day of admission and at weekly intervals thereafter till discharge, high vaginal swab from mothers collected prior to delivery, swabs from all attending health care worker from palmer surface, fingers and webs of the hands twice a month during the study period.

\section{Sample of Air of different areas of NICU} will be taken twice a Month.

3. 1 to $3 \mathrm{~mL}$ of blood will be collected from the infants admitted to NICU by using standard aseptic technique for blood culture in blood culture bottle containing brain heart infusion broth (Narain et al., 2003) (Table.1).

All swabs were inoculated on sabouraud dextrose agar slants incubated at $37^{\circ} \mathrm{c}$ for 7 days.Air sample were taken by exposing sabouraud dextrose agar plates in different areas of NICU for 30 minutes. The blood culture bottles were incubated at $37^{\circ} \mathrm{C}$ and were shaken periodically. On $3^{\text {rd }}, 5^{\text {th }}$ and $7^{\text {th }}$ day subcultures were made on Sabouraud dextrose agar slants, for any candidial growth along with routine bacterial culture (Narain et al., 2003). 
After inoculation and incubation, culture tubes and plates were examined daily for their morphological and colonial characters. Any growth indicated was subcultured on 5\% sheep blood agar, Mac conkey's agar and Sabouraud's dextrose agar (SDA) with chloramphenicol $(0.05 \%)$ and incubated at $37^{\circ} \mathrm{C}$. The Candida spp. isolated was identified as per standard mycological techniques. Preliminary identification was done by colony morphology on SDA, germ tube test,chlamydospore formation and was confirmed by carbohydrate fermentation and assimilation test (McGinnis, 1980).

AFS was performed for FLK(25mg), itraconazole (ITR $10 \mathrm{mcg}$ ) and amphotericin B (AMB 100units) Nystatine (100 units) Ketoconazole $(10 \mathrm{mcg})$, Clotrimazole (10 mcg) using disc diffusion method on Mueller- Hinton agar supplemented with 2\% glucose and methylene blue $(5 \mathrm{mg} / \mathrm{ml})$. Zone diameters were interpreted as per the approved National Committee for Clinical Laboratory standards (NCCLS) guidelines. Quality control for AFS was performed using C.albicans - ATCC 90028, C. Parapsilosis - ATCC 22019 and Candida krusei - ATCC 6258.

Examine each plate after 20 to 24 hours of incubation. Measure the zone diameter to the nearest whole millimeter at the point at which there is a prominent reduction in growth.

\section{Results and Discussion}

Newborns in neonatal intensive care units (NICUs) are at especially high risk of infections because of a combination of innate characteristics including their fragile integumentary and underdeveloped immune systems as well as the frequent need for instrumentation (e.g. central venous catheters), invasive procedures and frequent contact with staff.
The present study was conducted to identify risk factors for Candida colonization and candidemia in neonates admitted in neonatal intensive care unit and identification of Candida spp. along with the prevalent antifungal susceptibility pattern.

The overall Candida colonization rate in neonates in the study is $47.31 \%$. This colonization rate is higher than the frequencies reported by Baley et al., (27\%) (Barry et al., 1996) Sharp et al., (28.2\%) Kirkpatrick et al., (1998) and Mendiratta et al., (2006) (33.9\%). This variation in rate of colonization probably depends upon management protocol and nature and intensity of routine antifungal antiseptic measures applied in a particular set up.

Oral colonization is lower than rectal and groin colonization. Colonization in neonates at different site was $50 \%$ (oral), $63.63 \%$ (groin) and $65.90 \%$ (rectal) (Table.2). Maximum colonization was seen in rectum (65.90\%). Phelps et al., (1986) and Hageman et al., (1985) also found in their studies that the lower digestive tract appears to be the first site of yeast colonization among most neonates in a special care unit and that yeasts readily spread from the anal region to the groins.

The gastrointestinal tract can serve as a reservoir from where the fungus can spread, particularly if there is a breach in mucosal lining and also due to poor local colonization resistance.

Colonization in preterm was $60.46 \%$, which is significantly higher than that in term neonates $35.29 \%$ (Table.3). Mendiratta et al., reported $33.9 \%$, where as Singh et al., (1999) reported $74.4 \%$ colonization in preterm neonates. Colonization in preterm neonates is higher than term neonates because of the relative immunodeficiency in 
the preterm infant such as decreased skin and mucosal integrity, decreased function of neutrophils, and the relative quantitative deficiency of protective maternal IgA to Candida.

Candida colonization in low birth weight $(<$ $1.5 \mathrm{~kg}$ ) neonates is $76.19 \%$ whereas neonates $>1.5 \mathrm{~kg}$ birth weight had $38.88 \%$ colonization rate. Baley et al., reported $26.7 \%$ and A. M. Sharp et al reported $57.1 \%$ candida colonization rate in low birth weight $(<1.5 \mathrm{~kg})$ neonates.

Colonization rate in preterm neonates who were on IV antibiotics was $70.58 \%$ which is lower than that reported by Mendiratta et al., $82.22 \%$ (Table 4). Steroids and antibiotics are known to suppress immune system and their administration to immunodeficient preterm neonates promotes colonization. The duration of broad-spectrum antibiotic therapy is a potent factor that independently promotes fungal growth as measured through the colonization index in nonneutropenic ICU patients hospitalized for more than 7 days.

Vaginal Candida colonization in pregnant women were $31.12 \%$.

Isolates of Candida from preterms and vagina of their respective mothers were similar in species and antibiotic sensitivity pattern in 16 of them, colonization of preterm neonates born vaginally in vaginally colonized mothers was significantly more which shows that vaginal colonization / infection is an important risk factor for the colonization in neonates. Hence, i) mandatory screening of all pregnant women for Candida , irrespective of symptoms and ii) treatment of all pregnant women irrespective of vaginal colonization or infection is necessary to prevent colonization and subsequent infection of the neonates, especially preterm neonates.
The Candida spp. isolated from the neonates in our study was very similar to those reported in similar settings by others. In our study commonest cause of colonization is Candida albicans (56.81\%) which is in accordance with Baley et al., 62\%, Sharp et al., (1992) 67.4\%, and Mendiratta et al., (2006) 45.6\%. Other Candida spp. causing colonization were C. tropicalis, C. glabrata, C. krusei, C. parasilosis and C. guilleirmondii (Table.8).

Yeast carriage was also seen on hands of 6 health care workers, from the surface of 2 $\mathrm{NG}$ tube and $1 \mathrm{IV}$ line. Again C. albicans was most common isolate in health care workers. Candida parasilosis and C. tropicalis were also isolated (Table.8).

Trofa et al., (2008) have documented C.parapsilosis as an emerging fungal pathogen and a major threat for future especially among neonates in NICU's and the incidence of C.parapsilosis may continue to rise as it frequently colonises the hands of health care workers and has high affinity for parenteral nutrition.

The hands of HCW and environmental surfaces are newly-appreciated potential reservoirs for nosocomial strains of Candida. Use of multiple invasive devices, such as catheters and endotracheal tubes may be responsible for the nosocomial spread of pathogens through the hands of healthcare workers (HCW).

The transmission of candida from health care staff to neonates can be prevented by following current best practices for hand hygiene which include the cleaning or degerming of hands before and after patient contact, after touching patient, equipment or environmental surfaces, before performing invasive procedures and after removing gloves. 
None of the environmental sample were positive for Candida.

In the blood samples from NICU, overall incidence of candidemia was $11.1 \%$ (Table.6) which is close to $9 \%$ as reported by Daniel et al., (2010).

Incidence is significantly higher in neonates weighing $\leq 1500 \mathrm{~g}(13 / 17,76.47 \%)$ than in those $\geq 1500 \mathrm{~g}(5 / 17,29.41 \%)$ (Table.7).

All 17(100\%) neonates were on I V antibiotics and this inference is in accordance with $100 \%$ reported by $\mathrm{S}$ Narayan et al., (2003) (Table.7). A restrictive policy of antibiotic use should be implemented to decrease Candida colonization/infection rates to reduce the morbidity and mortality associated with these infections. Out of these 17 neonates, 8 $(47.05 \%)$ neonates had Candida colonization. Monitoring of Candida colonization in NICU patients is crucial because colonization is a strong and reliable marker for potential invasive infection.

Candida albicans was most common spp. causing $41.17 \%$ candidemia in this study which is echoed in studies of Narayan et al., (2003) (53.33\% ) \& Scott et al., (1996) (57.9\%). Other Candida spp. causing candidemia were $C$. tropicalis, $C$. glabrata, C. krusei (Table.8).

Only one $(5.88 \%)$ neonate, out of 17 neonates with candidemia succumbed to infection. Jyotsna et al., and Scott et al., (1996) reported $52.6 \%$ and $13 \%$ mortality rate respectively in neonates with candidemia.

There is a wide range of variability in the reported frequencies of candida infection in NICUs due to several factors. Inconsistencies in surveillance culture policies makes it difficult to compare the incidence rates of different settings and institutions.

Table.1 Details of clinical samples for candida isolation

\begin{tabular}{|c|c|c|c|}
\hline S.N. & Type of sample & Number & $\begin{array}{l}\text { Number of sample } \\
\text { positive for Candida }\end{array}$ \\
\hline 1. & $\begin{array}{l}\text { Oral, rectal, umbilical and groin swab } \\
\text { sample from neonates in NICU }\end{array}$ & $\begin{array}{l}1548 \text { (from } 186 \\
\text { neonates) }\end{array}$ & $\begin{array}{l}377 \text { (from } 88 \text { neonates) } \\
155(31.12 \%)\end{array}$ \\
\hline 2. & Vaginal swab from pregnant women & 498 & $6(10.52 \%)$ \\
\hline 3. & $\begin{array}{l}\text { Swab from hands of health care staff } \\
\text { in NICU }\end{array}$ & 57 & \\
\hline 4. & Swab from nasogastric tube and iv line & 29 & $3(10.34 \%)$ \\
\hline & total swab samples & 2132 & 541 \\
\hline
\end{tabular}

Table. 2 Rate of colonization at various site in 88 colonized neonates

\begin{tabular}{|l|l|}
\hline Site of colonization & No. of Neonate \\
\hline Oral & $44(50 \%)$ \\
\hline Rectal & $58(65.90 \%)$ \\
\hline Groin & $56(63.63 \%)$ \\
\hline Umblicus & $28(31.18 \%)$ \\
\hline
\end{tabular}


Table.3 Factors influencing colonization in neonates

\begin{tabular}{|c|c|c|c|}
\hline & \multicolumn{2}{|c|}{ Colonization } \\
\hline & & Yes & No \\
\hline $\begin{array}{l}\text { Sex } \\
\text { Male } \\
\text { Female }\end{array}$ & $\begin{array}{l}116 \\
70\end{array}$ & $\begin{array}{c}56(48.27 \%) \\
32(45.71 \%)\end{array}$ & $\begin{array}{l}60(51.73 \%) \\
38(54.29 \%)\end{array}$ \\
\hline $\begin{array}{l}\text { Term } \\
\text { Preterm }\end{array}$ & $\begin{array}{l}100 \\
86\end{array}$ & $\begin{array}{l}36(36 \%) \\
52(60.46 \%)\end{array}$ & $\begin{array}{l}64(64 \%) \\
34(39.54 \%)\end{array}$ \\
\hline $\begin{array}{c}\text { Birth weigh } \\
<1.5 \mathrm{~kg} \\
>1.5 \mathrm{~kg}\end{array}$ & $\begin{array}{l}42 \\
144\end{array}$ & $\begin{array}{l}32(76.19 \%) \\
56(38.88 \%)\end{array}$ & $\begin{array}{l}10(23.81 \%) \\
88(61.12 \%)\end{array}$ \\
\hline $\begin{array}{l}\text { Type of delivery } \\
\text { Vaginal } \\
\text { Caesarian }\end{array}$ & $\begin{array}{l}142 \\
44\end{array}$ & $\begin{array}{l}70(49.29 \%) \\
18(40.91 \%)\end{array}$ & $\begin{array}{l}72(50.71 \%) \\
26(59.09 \%)\end{array}$ \\
\hline $\begin{array}{l}\text { Antibiotics } \\
\text { Received } \\
\text { Not received }\end{array}$ & $\begin{array}{l}132 \\
54\end{array}$ & $\begin{array}{l}76(57.57 \%) \\
12(22.22 \%)\end{array}$ & $\begin{array}{l}56(42.43 \%) \\
42(77.78 \%)\end{array}$ \\
\hline $\begin{array}{l}\text { Intubation } \\
\text { Yes } \\
\text { No }\end{array}$ & $\begin{array}{l}38 \\
148\end{array}$ & $\begin{array}{l}30(78.97 \%) \\
58(39.19 \%)\end{array}$ & $\begin{array}{l}8(21.03 \%) \\
90(60.81 \%)\end{array}$ \\
\hline $\begin{array}{l}\text { APGAR } \\
0-5 \\
>5\end{array}$ & $\begin{array}{l}15 \\
176 \\
\end{array}$ & $\begin{array}{l}13(86.66 \%) \\
75(42.61 \%)\end{array}$ & $\begin{array}{l}2(13.34 \%) \\
96(57.39 \%)\end{array}$ \\
\hline
\end{tabular}

Table.4 Candida colonization in Preterm neonates on IV antibiotic

\begin{tabular}{|l|l|l|l|}
\hline \multirow{2}{*}{} & No. & \multicolumn{2}{|c|}{ colonization } \\
\cline { 3 - 4 } & & Yes & No \\
\hline $\begin{array}{l}\text { Preterm neonates } \\
\text { with IV antibiotics }\end{array}$ & 68 & $48(70.58 \%)$ & $20(29.42 \%)$ \\
\hline $\begin{array}{l}\text { Preterm neonates } \\
\text { without IV antibiotics }\end{array}$ & 18 & $4(22.22 \%)$ & $14(77.78 \%)$ \\
\hline
\end{tabular}

Table.5 Colonization in vaginally delivered neonates in relation to colonization of vagina

\begin{tabular}{|l|l|l|l|}
\hline \multirow{2}{*}{ Swab taken } & \multicolumn{2}{|c|}{ vagina colonized } & \multicolumn{2}{c|}{ Neonates colonized } \\
\cline { 3 - 4 } & Yes 29(35.36\%) & Yes & \multicolumn{1}{c|}{ No } \\
\cline { 2 - 4 } & No $31(64.66 \%)$ & $22(75.86 \%)$ & $9(24.14 \%)$ \\
\hline Nos(n)82 & & $44(42.50 \%)$ & $29(58.50 \%)$ \\
\hline Total(n)186 & & $88(47.31 \%)$ & $60(57.70 \%)$ \\
\hline Total $(n) 186$ & & 88 & $98(52.68 \%)$ \\
\hline
\end{tabular}


Table.6 Blood sample

\begin{tabular}{|c|l|l|c|}
\hline S.No. & Blood sample from NICU & No. of sample & $\begin{array}{l}\text { Candida positive } \\
\text { sample }\end{array}$ \\
\hline 1. & $\begin{array}{l}\text { Neonates included in } \\
\text { colonization study }\end{array}$ & 60 & $8(13.33 \%)$ \\
\hline 2. & $\begin{array}{l}\text { Neonates not included in } \\
\text { colonization study }\end{array}$ & 93 & $9(9.67 \%)$ \\
\hline & Total & 153 & $17(11.11 \%)$ \\
\hline
\end{tabular}

Table.7 Clinical features in neonates with systemic Candidiasis

\begin{tabular}{|l|c|}
\hline Underlying clinical features & $\mathrm{n}(\%)$ \\
\hline Antibiotic therapy & $17 / 17(100)$ \\
\hline Low birth weight & $13 / 17(76.4)$ \\
\hline Preterm infants & $10 / 17(58.82)$ \\
\hline Respiratory distress syndrome & $12 / 17(70.58)$ \\
\hline Ventilator therapy & $8 / 17(47.05)$ \\
\hline Necrotising enterocolitis & $2 / 17(11.7)$ \\
\hline Candida colonization & $8 / 17(47.05)$ \\
\hline Central line & $5 / 17(29.41)$ \\
\hline
\end{tabular}

Table.8 Candida spp. isolated from different type of sample

\begin{tabular}{|l|l|l|l|l|l|l|}
\hline & $\begin{array}{l}\text { swab samples } \\
\text { from neonates }\end{array}$ & $\begin{array}{l}\text { Blood } \\
\text { samples } \\
\text { from } \\
\text { neonates }\end{array}$ & $\begin{array}{l}\text { Swab } \\
\text { sample from } \\
\text { hands of } \\
\text { Staff }\end{array}$ & $\begin{array}{l}\text { Vaginal } \\
\text { swab from } \\
\text { pregnant } \\
\text { mother }\end{array}$ & total & $\begin{array}{l}\text { Percen- } \\
\text { tage }\end{array}$ \\
\hline $\begin{array}{l}\text { No.of sample } \\
\text { positve for } \\
\text { candida }\end{array}$ & $\begin{array}{l}88+3 \\
\text { (double } \\
\text { infection) }\end{array}$ & 17 & 6 & 29 & 143 & \\
\hline C. albicans & 50 & 7 & 3 & 21 & 81 & 56.64 \\
\hline C. tropicalis & 23 & 3 & 1 & 6 & 33 & 23.07 \\
\hline C. glabrata & 9 & 2 & & 2 & 13 & 9.09 \\
\hline C. krusei & 3 & 5 & & & 8 & 5.59 \\
\hline C.parasilosis & 4 & & 2 & & 6 & 4.54 \\
\hline C. guilleirmondii & 2 & & & & 2 & 1.39 \\
\hline
\end{tabular}

No candida spp. was isolated from environment of NICU. 
Table.9 Antifungal susceptibility of the isolated candida spp.(n-143)

\begin{tabular}{|l|l|l|l|l|l|l|l|}
\hline $\begin{array}{l}\text { S. } \\
\text { N. }\end{array}$ & Isolated Candida & $\begin{array}{l}\text { NYS } \\
\mathrm{n}(\%)\end{array}$ & $\begin{array}{l}\text { A B } \\
\mathrm{n}(\%)\end{array}$ & $\begin{array}{l}\text { Kt } \\
\mathrm{n}(\%)\end{array}$ & $\begin{array}{l}\text { FlC } \\
\mathrm{n}(\%)\end{array}$ & $\begin{array}{l}\text { CC } \\
\mathrm{n}(\%)\end{array}$ & $\begin{array}{l}\text { IT } \\
\mathrm{n}(\%)\end{array}$ \\
\hline 1. & C. albicans $(81)$ & $81(100)$ & $81(100)$ & $60(74.04)$ & $66(82.71)$ & $55(67.90)$ & $35(43.20)$ \\
\hline 2. & C. tropicalis $(33)$ & $33(100)$ & $33(100)$ & $18(54.54)$ & $26(78.78)$ & $17(51.51)$ & $16(48.48)$ \\
\hline 3. & C. glabrata $(13)$ & $13(100)$ & $13(100)$ & $6(46.15)$ & $2(15.38)$ & $3(23.07)$ & $6(46.15)$ \\
\hline 4. & C. krusei(8) & $8(100)$ & $8(100)$ & $4(50)$ & 0 & $2(25)$ & $2(25)$ \\
\hline 5. & C.parasilosis $(6)$ & $6(100)$ & $6(100)$ & $4(66.66)$ & $5(83.33)$ & $4(66.66)$ & $2(33.33)$ \\
\hline 6. & C. guilleirmondii(2) & $2(100)$ & $2(100)$ & $1(50)$ & $2(100)$ & $2(100)$ & $1(50)$ \\
\hline & Total=143 & 143 & 143 & $93(65.03)$ & $102(71.32)$ & $83(58.04)$ & $62(43.35)$ \\
\hline
\end{tabular}

In the current study, Amphotericin B $(100 \%)$ and Nystatin $(100 \%)$ was the most effective antifungal agent) (Table.9). In India, amphotericin B is the drug of choice for invasive candidiasis with low or no resistance reports. Candida isolates also showed lower resistance rates to Fluconazole $(28.68 \%)$ in our study which is in accordance to $24 \%$ reported by Narang et al., and $18.75 \%$ reported by Narayan et al. All C. krusei isolates were resistant to Fluconazole. The same was also reported by Narayan et al., and Madhu Sharma et al., (2011).

Due to lower rate of resistance it is still a useful antifungal agent in prophylaxis of candida infection. Though there are various reports from our country showing increasing trend towards fluconazole resistance especially among non-albicans Candida which warrants its judicious use as a prophylactic agent in hospitals

In conclusion, Candida Parapsilosis is an emerging fungal pathogen and incidence of infection caused by it may continue to rise because it frequently colonizes hands of the health care worker \& has high affinity for transmission via paranteral nutrition. This nosocomial transmission of candida can be prevented by strictly following hand hygiene practices.

\section{References}

Agarwal, J., Bansal, S., Malik, G.K., and Jain, A. 2004. Trends in Neonatal Septicemia: Emergence of Nonalbicans Candida. Indian Pediatrics, 41: 712-15.

Asmundsdottir, L.R., Erlendsdottir, H., Haraldsson, G., Guo, H., Xu, J., Gottfredsson, M. 2008. Molecular Epidemiology of Candidemia: evidence of clusters of smoldering nosocomial infections. Clin. Infect. Dis., 47(2): 17-24.

Baley, J.E., Kleigman, R.M., Boxerbaum, B., Fanaroff, A.A. 1986. Fungal colonization in the very low birth weight infant. Pediatrics, 78: 225-32.

Barry, A.L., Brown, S.D. 1996. Fluconazole disk diffusion procedure for determining susceptibility of Candidaspecies. J. Clin. Microbiol., 34: 2154-7. (PMC free article) (PubMed)

Bendel, C.M. 2003. Colonization and epithelial adhesion in the pathogenesis of neonatal candidiasis. Semin Perinatol., 27(5): 357-364.

Benjamin, D.K. Jr, Stoll, B.J. 2006. Infection in late preterm infants. Clin. Perinatol., 33: 871-82.

Blot, S., Dimopoulos, G., Rello, J., Vogelaers, D. 2008. Is Candida really 
a threat in the ICU? Curr. Opin. Crit. Care, 14(5): 600-4.

Castagnola, E., Buratti, S. 2009. Clinical aspects of invasive candidiasis in paediatric patients. Drugs, 69(Suppl.1): 45-50.

Chapman, R.L. 2007. Prevention and treatment of Candida infections in neonates. Semin Perinatol., 31(1): 3946.

Daniel, K., Benjamine, Jr, Barbara, J., Stoll, Marie, G., Gantz. 2010. Neonatal candidiasis: Epidemiology ,Risk factor. And Clinical Judgment, Pediatrics, 126.

Hageman, J.R., Stenske, J., Kueler, H., Randall, E. 1985. Candida colonization and infection in very low birth weight (VLBW) infants in the intensive care nursery. Pediatr. Res., 19: 1407A.

Karlowicz, M.G., Rowen, J.L., and BarnesEley, M.L. 2002. The role of birth weight and gestational age in distinguishing extremely low birth weight infants at high risk of developing candidemia from infants at low risk: a multicenter study. Pediatr. Res., 51: 301-8.

Kaufman, D., Boyle, R,. Hazen, K. 2001. Fluconazole prophylaxis against fungal colonization and infection in preterm infants. $N$ Engl. J. Med., 345: 1660-1666.

Kirkpatrick, W.R., Turner, T.M., Fothergill, A.W., McCarthy, D.I., Redding, S.W., Rinaldi, M.G., et al. 1998. Fluconazole disk diffusion susceptibility testing of Candida species. J. Clin. Microbiol., 36: 3429-32. (PMC free article) (PubMed)

Makhoul, I.R., Sujov, P., Smolkin, T., Lusky, A., and Reichman, B. 2002. Epidemiological, clinical, and microbiological characteristics of late- onset sepsis among very low birth weight infants in Israel: a national survey. Pediatrics, 109: 34-9.

McGinnis, M.R. 1980. Laboratory Handbook of Medical Mycology. New York : Academic Press. Yeast Identification, p. 337-73

Mendiratta, D.K., Rawat, V., Thamke, D., Chaturvedi, P., Chhabra, S., and Narang, P. 2006. Candida colonization in preterm babies admitted to neonatal intensive care unit in the rural setting. Ind. J. Med. Microbiol., 24(4): 263267.

Narain, S., J.S. Shastri, M. Mathur, P.R. Mehta. 2003. Neonatal systemic candidiasis in a tertiary care centre; Indian J. Med. Microbiol., 21(1): 5658.

Narang, A., Agarwal, P.R., Chakrabarti, A., Kumar, P. Epidemiology of systemic candidiasis in a tertiary care neonatal unit. J. Trop. Pediatrics.

Narayan, S., J.S. Shastri, M. Mathur, P.R. Mehta. 2003. Neonatal systemic candidiasis in a tertiary care centre; Indian J. Med. Microbiol., 21(1): 5658.

National Committee for Clinical Laboratory Standards. 2004. Methods for antifungal disc diffusion susceptibility testing yeast: Approved guideline $\mathrm{M}$ 44A. Wayne, PA : NCCLS.

Phelps, M., Ayliffe, G.A.J., Babb, J.R. 1986. An outbreak of candidiasis in a special care baby unit: the use of a resistogram typing method. J. Hosp. Infect., 7: 13-20.

Roilides, E., Farmaki, E., Evdoridou, J., Francesconi, A., Kasai, M., Filioti, J., Tsivitanidou, M., Sofianou, D., Kremenopoulos, G., and Walsh, T.J. 2003. Candida tropicalis in a Neonatal Intensive Care Unit: Epidemiologic and Molecular Analysis of an Outbreak of Infection with an 
Uncommon Neonatal Pathogen. $J$. Clin. Microbiol., 41(2): 735-41.

Scott, K. 1996. Fridkin and William R. Jarvis. Epidemiology of Nosocomial Fungal Infections. Clin. Microbiol. Rev., Vol. 9(4) p. 499-511.

Sharma, M., Yadav, S., Aparna, Chaudhary, U. 2011. Candida blood stream infection in neonates. Int. J. Pharma \& Biosci., Vol 2/Issue 2/Apr-Jun 2011.

Sharp, A.M., Odds, F.C., and Evans, E.G. 1992. Candida strains from neonates in a special care baby unit. Arch. Dis. Child, 67: 48-52.

Singh, K., Chakrabarti, A., Narang, A., and Gopalan, S. 1999. Yeast colonization and fungemia in preterm neonates in tertiary care centre. Indian J. Med. Res., 110: 169-73.

Stoll, B.J., Hansen, N., Fanaroff, A.A., Wright, L.L., Carlo, W.A., Ehrenkranz, R.A,. Lemons, J.A., Donovan, E.F., Stark, A.R., Tyson, J.E., Oh, W., Bauer, C.R., Korones, S.B., Shankaran, S., Laptook, A.R., Stevenson, D.K., Papile, L.A., and Poole, W.K. 2002. Late-onset sepsis in very low birth weight neonates: the experience of the NICHD Neonatal
Research Network. Pediatrics, 110: 285-91.

Stronati, M., Decembrino, L. 2006. Neonatal invasive candidiasis. Minerva Pediatr., 58: 537-49.

Trofa, D., Gacser, A., Nosanchuk, J.D. 2008. Candida parapsilosis, an emerging fungal pathogen. Clin. Microbiol. Rev., 21: 606-625.

Waggoner-Fountain, L.A., Walker, M.W., Hollis, R.J., Pfaller, M.A., Ferguson, J.E., Wenzel, R.P., et al. 1996. Vertical and horizontal transmission of uniqe Candida species to premature newborns. Clin. Infect. Dis., 22: 803-8.

William, G., Merz, Roderick, J., Hay. 1997. Topley \& Wilson's microbiology \& microbial infection $10^{\text {th }}$ edition, Medical Mycology. Richardson \& Warnock 1997;Sullivan \& coleman 2002. P.584.

Winner, H.I. and Hurley. 1964. Candida albicans. J \& A. Churchill Ltd. London.

Wolf, H.W., et al. 1959. sampling microbiological aerosols, Public Health Service Pub. No. 686, Washington, D. C., U.S. Government Printing Office.

\section{How to cite this article:}

Kavita Bansiwal, Abhishek Binnani and Priyanka Soni Gupta. 2016. Study of Candida Colonization and Candidemia in Neonates Admitted in Neonatal Intensive Care Unit at a Tertiary Care Institute of Bikaner, Rajasthan, India. Int.J.Curr.Microbiol.App.Sci. 5(10): 156165. doi: http://dx.doi.org/10.20546/ijcmas.2016.510.018 